\title{
TIMI Coronary Thrombus Grade 4
}

National Cancer Institute

\section{Source}

National Cancer Institute. TIMI Coronary Thrombus Grade 4. NCI Thesaurus. Code

C119586.

Large size definite thrombus, with the largest dimension greater than or equal to 2 vessel diameters. (Gibson, C. M., de Lemos, J. A., Murphy, S. A., Marble, S. J., McCabe, C. H., Cannon, C. P., Antman, E. M., Braunwald, E. Combination therapy with abciximab reduces angiog raphically evident thrombus in acute myocardial infarction: a TIMI 14 substudy Circulation. 2001;103(21):2550-4.) 